\title{
Therapy in the gray zone: psychiatry recalled
}

\author{
Mary V. Seeman \\ We tend to simplify history ... \\ - Primo Levi, The Drowned and the \\ Saved $^{1}$
}

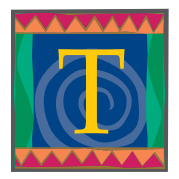

hea, if she were alive today, would be over 90 years old. She was the first woman I met when I came as a new resident in psychiatry to New Branch III, Manhattan State Hospital, in 1961. One of the functions Thea assumed was to greet newcomers. She was a very large, imposing black woman, born in East Harlem, and a hospital inmate since 1930. Thea looked fierce and, perhaps for this reason, held a special position on the research ward to which I was assigned: she was a bridge between patients and staff. She had to ensure, for instance, that the 30 women housed in New Branch III arrived at their sheltered workshop on time and fulfilled their daily work quota.

The psychiatric hospital then, as now, served a double purpose: to treat and cure where possible, but also to protect society from those judged insane and potentially dangerous. There was a chain of command. The administration at Manhattan State Hospital consisted of the psychiatric heads of the various wards, who were answerable to the director of the hospital - who, in turn, reported to the New York Commissioner of Mental Health. But, in those days, the head nurses were the real chiefs. The charge nurses, their aides, and the psychiatric residents followed orders and were quickly acculturated into the seemingly unreconcilable roles of healer and jailer.

I was soon to find out that there were unspoken rules in New Branch III that could not be broken by patients or by psychiatric trainees: total compliance with the protocol of experimental medications (we were running a research unit, and part of the director's income came from research grants for clinical trials of new drugs); and total compliance with the work program (ours was a model sheltered workshop program whose prestige and funding depended on productivity). The coercive nature of these rules and the reasons behind them were only vaguely apparent to me back then.

Thea, alone among the women residents, occupied a single room. Even though her living conditions were better than those of the patients around her, she was not a happy person. She was often asked by the head nurse to carry out orders that forfeited her the respect of other patients. At the same time, through recent reforms of the hospital system, the head nurse was gradually losing the almost absolute powers she had once wielded. We were trying to become a democratic therapeutic community, an idea introduced to the US by the charismatic British psychiatrist Maxwell Jones (1907-1990), who advocated flattening traditional hierarchies to create a community of equals among patients, nurses and doctors. This meant that not only staff but also patients routinely participated in community meetings at which medications, privileges and discharges were discussed and where dissatisfaction and complaints could be voiced. Distinctions between staff and patients were discouraged, and so staff gradually shed their uniforms and badges. This new democracy began to cut into the authority of the head nurse.

Our director, paradoxically, acquired extra power. He was conducting new clinical trials into which residents were co-opted as participants. Just as Thea was not happy about some of the

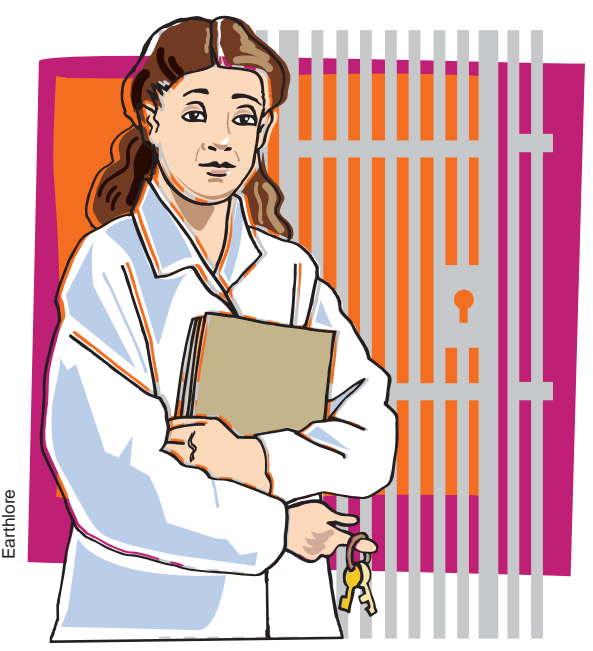

work she had to do, neither were we, the residents, with ours. We gave patients mescaline intravenous infusions on the theory that an induced psychosis would somehow terminate the original one. Unfortunately, most patients got worse. They hated how mescaline made them feel, but we made them go through the treatment nonetheless. They didn't have the right to refuse.

The ward operated on a token system. Tokens were handed out for good behaviour and could be redeemed for treats at the tuck shop or for outside privileges. Thea was in charge of verifying the good behaviour. Being human, she had her favourites and her scapegoats. A charge of bad behaviour resulted in privileges being revoked. Goodbehaviour tokens were awarded for satisfactory performance in the workshop. The quota of packages that the patients produced each day were also part of the economy of the real world, since the funds from the packaging financed the director's research. $\mathrm{Pa}$ tients had to get up on time, quickly dress and eat breakfast and then spend the day packing. The workshop doubled as a dining room. Packaging material was cleared temporarily and 
trays set before the patients. The diet was mainly starch. Hot dogs and beans were standard, as was stale bread. As soon as the food was cleared, the packaging materials came out again. Although the principles of a therapeutic community should have allowed patients to elect their own manager, Thea was appointed to that position by the head nurse. When the pace of work slackened, Thea was not above threatening patients with restraints, heavier sedation or the cancellation of a weekend outing.

The psychiatric residents conducted sodium amytal interviews with new patients. The idea was that patients either didn't remember or didn't want to tell the truth about their past, and that sodium amytal would make them reveal it, willingly or not. Keeping things private was discouraged. Secrets were told and recorded in the psychiatric files, open to scrutiny by people whose right to that information was questionable. There was no confidentiality and little freedom of movement. The ward was locked during the day so patients couldn't lie on their beds; they were confined inside the workshop area from 9 to 5 , to keep them producing. The staff, the residents and Thea kept the keys.

Although we think of the 1960s as a time when effective psychiatric treatments were lacking, there were paradoxically more therapies available on our ward than there are nowadays. Residents conducted several kinds of group therapy in addition to the milieu groups or ward meetings intended to foster a feeling of community. Gestalt groups were the most popular, but there was also psychodrama, role-playing, family therapy and even multifamily group therapy. Family therapy was often used in conjunction with insulin treatment, on the theory that induction of hypoglycemia would to lead to recovery in schizophrenia. When this treatment was new, a $90 \%-95 \%$ recovery rate was reported for it, far superior to current rates of recovery. Because patients routinely regressed during treatment, families were invited to take part in order to allow for rebirthing and re-rearing experiences.

The effectiveness of these therapies had variable measures. Group work was deemed effective on the basis of efficiency: all patients received a share of "doctor time" and all residents had "patient contact" sufficient for subsequent supervision with the director. Sleep therapy, which we used to keep agitated patients asleep for long periods of time, was an extremely effective intervention for making the ward a quieter place. There was also art therapy, and leisure time was spent playing cards (there was no television on the ward). Although a recent Cochrane review has come to the conclusion that the benefits or harms of art therapy remain unclear, it was definitely effective in allowing selected patients off the ward one day a week, away from the numbing routine of the workshop and into the company of an extraordinary art therapist, Estelle Ades, who served her artists tea in real china cups and engaged them in conversation.

By 1966, when I left New York, state and federal courts had ruled that people with mental illness retained the legal right to refuse treatment and could be committed involuntarily to mental institutions only if they posed a clear and present danger to themselves or others. With few people wanting in and only those who were dangerous being admissible against their will, the census of psychiatric hospitals fell and the era of large long-stay psychiatric hospitals, Nurse Ratchetts and bridging patients like Thea were over. The sheltered workshop closed. Research came under new administration. New brooms swept New Branch clean. Thea died of breast cancer, with few to mourn her passing.

We now live in an era in which treatments for which there is no hard evidence - art therapy will serve as an example - are no longer provided. Accurate diagnosis has taken centre stage in psychiatry, requiring patients to endorse or deny a detailed series of symptoms. As a result, therapeutic conversations too often take the form of symptom checking. And, despite the scientific evidence that currentday treatments work, they are still seen by patients not as a cure but as a punishment, an intrusion, a coercion. Patients today complain about the issues very similar to the ones they complained about when I was a resident almost 50 years ago: formulaic treatment, lack of autonomy, lack of power to effect change and perceived lack of respect from staff.

Does today's "evidence" take into account patient perspectives? It has been argued that facts are facts only within the theoretical structure in which they are embedded, and that results are deemed "positive" or "negative" depending on the outcome that is considered relevant. When the goal was work productivity, token economies were effective. Looking at token economies now and asking a different question - "Do they improve negative symptoms?" - Cochrane reviewers can find no proof of effectiveness. When a peaceful ward was a desired outcome, hydrotherapy, insulin therapy and convulsive therapy were once judged effective. When emptying hospitals was the goal, lobotomies were effective. And yet, even when we know that the effectiveness of our treatments depends on how we, not our patients, define good outcomes, coercive treatments and physical restraints - throwbacks to the early days of psychiatry - continue to be used. Chemical restraints today confer fewer immediate unpleasant effects than did earlier analogues, but they continue to pose uncertain and perhaps serious consequences if used over time. Despite contemporary commitment to a humanitarian vision, there is a tendency to see patients not as individuals but as representatives of a disease entity. The wrappings of a disease too often stand for the person under the wrap, in a form of unintentional dehumanization. The mental health care system is still bureaucratic - perhaps more so than ever before, as mergers transform hospitals into large conglomer- 
ates that are difficult to humanize and in which decision-makers are removed farther and farther from the bedside.

We know that professionals' views do not necessarily reflect the experience of patients. For instance, staff justify involuntary hospitalization, involuntary treatment and the use of physical restraints more frequently than patients do. This difference is probably a function of how the two groups evaluate the potential benefit of a treatment - how convinced they are about its ability to heal what they perceive to be the problem in need of healing. Psychiatric professionals and psychiatric patients rarely share the same perspective on what is fundamentally wrong. Bridging this chasm of incomprehension are individuals who, to borrow from Primo Levi's description of Nazi labour camps, occupy a "grey zone." They are functionaries selected from among the inmates or the trainees to assist the staff. Some are collaborators, prepared to compromise their principles for personal gain. Some use their position to advantage, making the lives of inmates a little easier. I'd like to think that Thea and I belonged to the second category.

Mary V. Seeman is Professor Emerita at the Centre for Addiction and Mental Health, University of Toronto, Toronto, Ont.

\section{Reference}

1. Levi P. The drowned and the saved [1986]. [Translated by Rosenthal R.] New York: Summit Books; 1988. ch 2.

\section{$C M A 7$ through the ages}

David McDonald

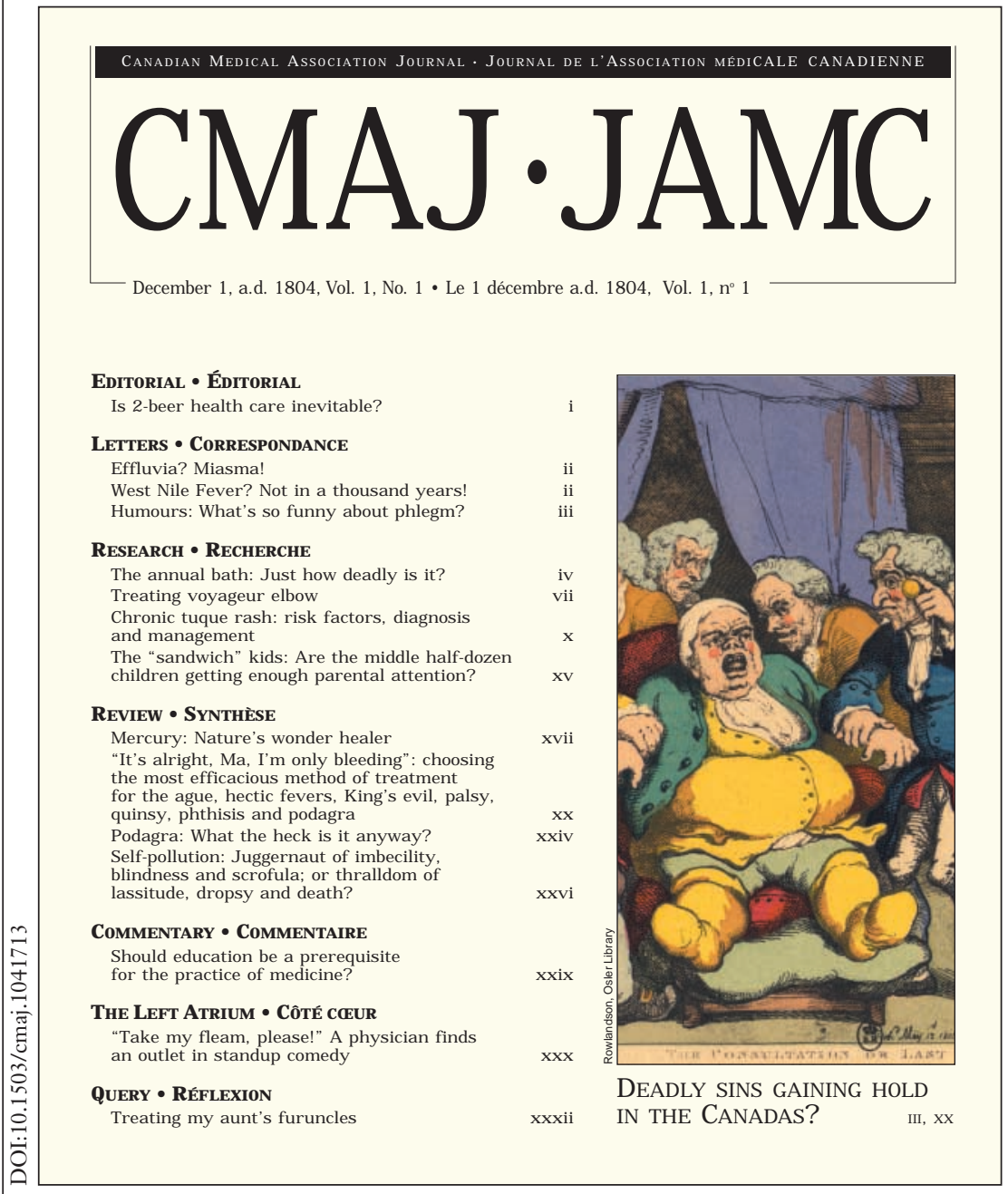

